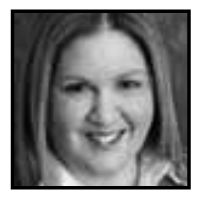

\title{
Executive Function in the Classroom: Neurological Implications for Classroom Intervention
}

\author{
Harriet Greenstone, Centre MDC
}

\begin{abstract}
Executive function skills are critical for both school and personal success, but have been traditionally under-addressed in academic settings. Recent advances in the field of neuroscience, and specifically those dealing with neuroplasticity, have provided new understanding of the causes of executive dysfunction and how we can use this information to remediate these weaknesses in the classroom, even for those with typical executive function development, by teaching these skills as part of the curriculum.
\end{abstract}

\section{Introduction}

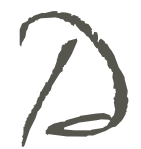

espite increased efforts in recent years toward zero tolerance for aggression, oppositional behaviour, and bullying, these behaviours persist in our classrooms. And despite our many pedagogical and curricular advances, too many students are still not completing high school, or are graduating without the skill sets necessary to succeed in post-secondary studies.

This article proposes that although educators may be aware of executive function skills, they may be overlooking their important implication in the foundation (and thus the remediation) of both academic and behavioural problems. Executive function skills are a collection of skills that are critical for goal-directed behaviours, social behaviours, and emotional well-being. It's hard to imagine being successful in the classroom, or indeed in life, without them. They are at least as important as reading and mathematics skills, arguably even more important, yet while progress has 
been made in the research domain for executive functioning, much less is being seen in practice.

There is no definitive list of what constitutes executive function skills. Researchers generally agree on the content, but there is often overlap and differential labelling of the various skills. A good working model can be found in the Behavior Rating Inventory of Executive Function (BRIEF; Gioia, Isquith, Guy, \& Kenworthy, 2000), which measures the executive function domains shown in the table below.

\section{Table 1}

\section{Executive Function Domains (BRIEF)}

DOMAIN

Inhibit

Shift

Emotional control

Initiate

Working Memory

Plan/Organize

Organization of materials

Monitor

\section{DESCRIPTION}

Ability to resist impulses and inhibit one's behaviour when appropriate.

Ability to switch attention, deal with transitions and tolerate change, think flexibly, shift focus.

Ability to control or modify one's emotional responses.

Ability to start an activity or task, to come up with one's own ideas and problem-solving approaches.

Ability to retain information in one's memory and actively use or manipulate it to complete a task (e.g., to follow complex instructions, or do multi-step activities such as mental arithmetic). Ability to set goals, anticipate future developments, predetermine steps necessary to complete a goal, organize information, identify key concepts or ideas, employ complex (or even simple) motor planning.

Ability to keep track of one's materials and belongings and maintain them in an organized state, available for use when needed.

Ability to assess one's progress on a task (monitoring accuracy, time management, effectiveness of strategies, etc.) and ultimate performance on the task, and the ability to monitor one's behaviours and the effect they have on others. 


\section{Executive Dysfunction: A Neurological Problem, Not a Character Flaw}

The frontal lobe, often referred to as the brain's "control centre," is considered the seat of executive functioning. This is where the anterior cingulate is located, which is often referred to as the "oops centre" because of its role in helping us anticipate risks and keeping us from acting in a way that is detrimental or inappropriate. This structure in the brain has been associated with many executive function skills, including emotional self-control, problem solving, divided attention, recognizing errors or conflicting information, and adaptive behaviour in changing circumstances (Allman, Hakeem, Erwin, Nimchinsky, \& Hof, 2001; Powell \& Voeller, 2004 ). Although the anterior cingulate is not the only part of the brain involved in executive function skills, its role is essential, and demonstrates that the roots of executive dysfunction lie in the brain, not in character flaws.

It's not surprising that a glitch in the neural circuitry of the frontal lobe can lead to problems in many areas of executive functioning-just as there are neurological, neuropsychological, and/or neurochemical underpinnings to many other disorders, including learning disabilities, ADHD, Obsessive Compulsive Disorder, Autism Spectrum Disorders, etcetera (all disorders with which executive function weaknesses are commonly associated).

What is surprising, however, is the disparate response to executive dysfunction in the classroom, relative to the specialized instruction techniques and other interventions that have been devised to help students with these other disorders. We certainly don't punish a child with dyslexia. But as Harvard psychologist Dr. Ross Greene (2009) points out in his book Lost at School, children with weak organizational, behavioural, or emotional skills are often met with discipline or consequences, even though they may not know what they have done wrong or how to do it right.

Hopefully, just as we no longer blame "refrigerator mothers" for autism, or demand that learning-disabled students "try harder!," our growing understanding of the neurological basis for executive dysfunction will lead to effective classroom interventions to help these students (and indeed even neurologically typical students) reach their academic and personal potential. 


\section{How to Know if a Student Has Weak Executive Function Skills}

Unfortunately, most students don't show up on the first day of school, clutching a pencil in one hand and a full psycho-educational report in the other. And even if they do, and you're lucky enough to find they have been tested for executive functioning, there's a caveat. Many measures test for a well-circumscribed and small subset of executive function skills, so the results cannot be generalized across the whole span of skills. You must also keep in mind that such testing can include detailed instructions (often repeated), ongoing feedback, and significant external structure. Also, such tests are typically administered in a private office, in a relatively stress-free environment, with only one supportive adult present. This is the best possible scenario for many children and adolescents with executive function difficulties, and one where they're very likely to do their best. These tests don't pretend to measure the whole range of the individual's executive skills, captured in a normal daily environment. And even when results do identify specific executive function weaknesses, they are often misunderstood, considered too small and specific to be of consequence, or beyond the scope of classroom intervention.

Broader, more "real life" measures can be obtained through behaviour ratings questionnaires completed by parents or caregivers, teachers, and even the students themselves if they are old enough. But by definition, these ratings are subjective.

All these findings can be helpful, but they should be augmented by a teacher's own observations in the classroom - and in many cases, that will be all there is to go on. Table 2 shows how weaknesses in some aspects of executive function might appear in school-aged children. Several of these skills are behavioural in nature, and others are metacognitive. An individual may be weak in some skills and competent or even strong in others. The weaknesses may be "stand-alone" or part of a mix of other difficulties. But whatever the presentation, the classroom challenges are the same.

Table 2

\section{Classroom Manifestations}

PROBLEMS WITH ..

Inhibit
MIGHT LOOK LIKE THIS ...

- Impulsivity - will often start on an activity before listening to instructions

- Difficulty staying in line when moving around the school, or even staying in the classroom

- Interrupting others or calling out in class

- Needing more adult supervision and structure 
PROBLEMS WITH ...

Shift
MIGHT LOOK LIKE THIS ...

- Difficulty changing tasks, places, approaches to problems

- Difficulty tolerating change (like a substitute teacher, or a change in a planned activity)

- Black and white thinking, can't see the grays, can't let go (not won't let go ... an important distinction)

\section{Emotional control}

- Outbursts, sudden/frequent mood changes, emotionally reactive, periods of excessive emotional upset

Initiate

- Needs to be told to start a task, even if they're willing to do it

- $\quad$ Ready to start a task, but doesn't know where to begin (i.e., doesn't know the first step, needs to have the steps broken down)

- Has trouble coming up with ideas (for a project, or even what to do in play time)

- Rarely takes initiative in chores or homework (doesn't know how)

Working memory

- $\quad$ Trouble remembering things (phone numbers, instructions)

- $\quad$ Losing track of what they're doing

- Forgetting the purpose of an errand

- Frequently failing to stick to an activity (poor sustained attention)

Plan/organize

- Underestimating time to complete a task, or level of difficulty

- Waiting to the last minute to begin a big project

- Mixes up the steps involved in a project, or in any multistep sequence

- $\quad$ Failing to understand main points in written or verbal material

- Losing track of homework assignments

- Getting caught up in details and losing track of the "big picture" 


\begin{tabular}{|c|c|}
\hline PROBLEMS WITH ... & MIGHT LOOK LIKE THIS ... \\
\hline $\begin{array}{l}\text { Organization of } \\
\text { materials }\end{array}$ & $\begin{array}{l}\text { - Trouble keeping school materials/belongings organized } \\
\text { - Leaving thing at home that should be at school, and vice } \\
\text { versa } \\
\text { - } \quad \text { Locker/desk/schoolbag is a mess } \\
\text { - } \quad \text { Frequently losing things } \\
\text { - } \quad \text { Failure to have materials ready for projects/assignments }\end{array}$ \\
\hline Monitor & $\begin{array}{l}\text { Difficulty assessing their own performance after finishing } \\
\text { a task, assessing what works and what doesn't work } \\
\text { Difficulty recognizing and keeping track of the effect their } \\
\text { behaviours have on others }\end{array}$ \\
\hline
\end{tabular}

Deficits in executive function have additional implications, beyond the classroom manifestations described in Table 2. For example, Elizabeth Kelley, Assistant Professor of Developmental Psychology at Kingston's Queens University, found that the emotional control measure of the BRIEF was identified as a significant predictor of being bullied, because a child with weak emotional control is so reactive (as cited in MacReady, 2011). A student with poor inhibitory and emotional control, who doesn't grasp the effect of his or her behaviours on others, will likely have impaired social skills. A student with weaknesses in working memory, organization, and the ability to plan and initiate tasks is likely to have deficits in such academic enablers as study skills, motivation, and/or engagement-which have been linked to academic success (DiPerna \& Elliott, 2002).

\section{Neuroplasticity and Remediation of Executive Dysfunction}

Children with deficits in attention, memory, learning, etcetera have traditionally been treated with school accommodations, medication when appropriate, and strategies and therapies designed to modify these weaknesses or at least teach the child to understand and manage them. These are all effective, and will continue to be a vital part of any intervention plan. 
But now, thanks to recent advances in the field of neuroscience, we can add to our repertoire of helpful interventions, even for such traditionally challenging areas as emotional regulation and lack of inhibitory control. Researchers like Canadian psychiatrist Norman Doidge have promulgated the notion of neuroplasticity, and provided new understanding of how the brain works. We now know that the right exercises and activities can build new circuitry in the brain, and strengthen areas of identified weaknesses. Essentially, the brain can learn to bypass neural pathways that aren't working and build new ones-not just in childhood, but through adolescence and even adulthood (Doidge, 2007).

In fact, fMRI studies indicate that some neurological functions, such as emotion processing and cognitive appraisal systems, only develop around the time of puberty. British researchers Blakemore and Choudhury (2006) speculated that these findings point to "a period of synaptic reorganisation" when adolescent brains might be particularly responsive to efforts to regulate executive function and social cognition.

Such efforts were the subject of a study by researchers Meltzer, Pollica, and Barzillai (2007), who examined methods of teaching executive function processes such as study skills in the classroom. In addition to providing many specific strategies, they proposed the following Principles of Effective Strategy Instruction:

- "Strategies for teaching executive function processes should be directly linked with the curriculum" - which appears to be more effective than when these skills are taught in isolation and are unrelated to the students' classroom work. Even if a student is participating in an extra-curricular study skills program, this could still be accomplished by the teacher and tutor collaborating, to ensure the material being used is based on current classroom subjects.

- "Metacognitive strategies should be taught explicitly" —using very literal and concrete terms, and including frequent modeling and repetition. It is important to also teach the students exactly how each strategy will help them (e.g., "This strategy will help you identify the key points in any text").

- "Strategies should be taught in a structured, systematic way"-again, incorporating frequent modeling, feedback, and opportunities for repeated practice, in order for these skills to be internalized and generalized. It is important to recognize that individual strategies are not "one size fits all." 
What works for one student might not work for another. Students should be encouraged to recognize what works best for them, so strategies can be adapted accordingly.

- "Strategy instruction should address students' motivation and effort" - It is critically important for students to (a) understand their own strengths and weaknesses, and (b) see that these strategies will lead to improved grades. Without either component, they are unlikely to use them. Step (a) can be challenging, when dealing with a student who has experienced years of failure and frustration and might be emotionally fragile. It is best accomplished in private discussions, with equal emphasis on both strengths and weaknesses, delivered in a clearly supportive, non-judgmental manner. A good approach to Step (b) would be to break down tasks or assignments into small, accomplishable units, so the students can experience successes and build on them.

Meltzer et al. also stressed the importance of developing a "culture of strategy use" in the classroom, by using methods such as encouraging students to keep individual notebooks of strategies that have worked best for them, and teachers grading students not just on the final results of tests or assignments, but also on the strategies they used to achieve them.

This approach to strategic learning is a natural fit with the work of Stanford University's Carol Dweck (2008). She believes that students who understand that brain power is dynamic (i.e., that it can be exercised and strengthened) fare better academically than those who believe their intellectual abilities were determined at birth and cannot be altered. The approaches she advocates, such as teaching students how brain exercises can stimulate neural growth (and improved grades), also strengthen important executive function skills like cognitive flexibility and self-monitoring.

Some specific strategies that may be taught to and employed by all students, not just those with executive dysfunction, would include time and work organizers, colour-coded and/or sectioned notebooks, calendars to keep track of deadlines and monitor progress, task analysis checklists, memory aids such as mnemonics, an understanding of whether they are strong auditory or visual learners and techniques adapted to those styles (audio recording of classes, detailed written instructions of assignments, etcetera), and opportunities to develop important work habits, such as breaking down problems or projects into manageable "chunks," realistically estimating time demands, generating alternative solutions and selecting the best one, and 
taking time to pause, reflect, and consider options before impulsively acting upon a first thought. These types of strategies have important implications even beyond the academic years. They encourage self-reliance and self-knowledge skills which would benefit any student, and should be applied in all classes, so they may begin to be generalized. Explaining to parents what appears to work best for their child may encourage them to reinforce these approaches at home when helping with homework or in other activities, again increasing the likelihood that the strategies will be internalized and generalized across environments.

Dealing with students with executive function weaknesses manifested in emotional, behavioural, and social challenges can be equally amenable to remediation, again based on an understanding of the deficits that give rise to these behaviours.

For example, Greene (1998) has done a great deal of clinical work with "explosive children." He explains that their "meltdowns" are manifestations of inflexibility, rather than opposition or bad behaviour. He offered at the time of this book a whole new way of thinking - that punishing such behaviour, or even rewarding the cessation of these outbursts, would do nothing to remediate the underlying problem. $\mathrm{He}$ believes that if these children could behave, they would behave; the problem is that they lack the skills to respond adaptively to the demands being placed on them.

Greene developed a process called Collaborative Problem Solving ("CPS"). He observed that children with emotional or behavioural challenges are almost always lacking a number of underlying executive function skills-such as the ability to deal with change, manage emotions, understand how their behaviours impact others, etcetera. He refers to these as "lagging skills." His CPS model is based on identifying the "unsolved problems," or antecedents that trigger the child's challenging behaviours (such as having a substitute teacher, or not knowing where to sit in the cafeteria), and then working collaboratively with the child to resolve the problems, one by one, by identifying and remediating the underlying lagging skills. He acknowledges it is a slow, repetitive process, but it is only by repetition that the child begins to learn to recognize his or her strengths and weaknesses, build confidence and motivation, and develop more appropriate adaptive responses to challenging situations.

The approaches of both Meltzer et al. and Greene to remediating weaknesses in executive function stress the importance of developing self-awareness, increasing motivation, and using repetition to encourage internalization and generalization (or in neurological terms, forging and strengthening new neural pathways). 
For illustration purposes, the following are hypothetical cases describing how these techniques could be applied in the classroom.

\section{Case 1 (Eric)—Executive Control Skills: Initiation, Organization, and Planning ${ }^{1}$ Scenario:}

Eleven-year-old Eric has to write a two-page essay on a country of his choosing. While the majority of his fellow fifth-graders dive into the task with confidence, Eric has no idea where to begin. He hasn't a clue where to find any of his research, let alone which country to choose. He conveniently leaves his agenda at school and although he pretends to be working in his room every evening, Eric actually spends the time playing computer games. A month later, Eric's parents are shocked to receive a call from his teacher, who informs them that Eric got a zero on his project-an assignment they never even knew he had.

\section{Challenges:}

Although Eric's teacher had provided the class with an outline of her expectations for the project and research tips, Eric was either in a daze during class or too ashamed to admit he hadn't understood the instructions. On his own, Eric is not able to break down a task. He has poor planning, time management, and organizational skills and does not know how to initiate a task. He feels stupid and grows increasingly anxious as the deadline approaches. So he does the only thing he can think of to make the problem go away-he ignores it.

\section{Remediation Strategies:}

Eric's parents and teachers need to collaborate to ensure he receives the additional support he requires both at school and at home around assignments. For example, until Eric has gained the confidence and skills to take responsibility for his work, the teachers could verify that assignments are properly recorded in Eric's agenda, which his parents would then check each night. Eric's teachers could also spend a few minutes with Eric privately (before or after school) to make sure he understands what is expected of him, and provide written instructions for both Eric and his parents to consult.

At home, a helpful strategy would be to teach Eric to break the project down into small, manageable parts. In mutually devising a time line with his parents, or a colour-coded "Assignment Calendar" (Spizman \& Garber, 1994) in which each step is identified and given a deadline, working backwards from the project's due date, Eric would have a visual reminder of his responsibilities that he could refer to again and again, and a way to concretize his progress. 
Eric would also benefit from study skills instruction, ideally built into the classroom curriculum (benefitting his peers as well), where he would learn techniques such as time management skills, brainstorming techniques, how to select a topic for an assignment, how to transfer thoughts onto paper, and how to compose a list of questions to be answered.

Above all, Eric needs support, encouragement, and reinforcement. Despite the fact that his behaviour may be frustrating to his parents and teachers, they need to remember that Eric is not intentionally acting lazy or difficult; he too is frustrated and anxious, at least partially as a result of his executive dysfunction, and his dishonesty was his way of compensating for feelings of inadequacy and embarrassment.

\section{Case 2 (Gaby)—Executive Control Skills: Emotional Control, Inhibit, Monitor} Scenario:

Fourteen-year-old Gaby has been diagnosed with ADHD-Mixed Type. Medication helps her focus attention, but she's still struggling with impulsivity and frequently annoys classmates with her constant questions and interruptions. After years of negative comments, rolling eyeballs, and being told she's too lazy to think for herself and just attention-seeking, Gaby has developed a hair-trigger temper and she's recently become involved in schoolyard fights with other girls.

\section{Challenges:}

Gaby's teacher has a good understanding of Gaby's problems, including difficulties predicting the probable outcomes of her actions, thinking of options to behaviours, negative thoughts that nobody likes her and she's "always getting blamed for nothing," and she understands how Gaby's behaviours disrupt and annoy others. But as much as she'd like to help Gaby, she doesn't know where or how to start to help her.

\section{Remediation Strategies:}

Gaby and her teacher would benefit from Greene's Collaborative ProblemSolving approach. The teacher has already made a good start, with her list of "lagging skills." She could speak to Gaby and her parents to see if she could come to school earlier, or stay a little later, so they'd have time to talk privately and try to work on these problems together. The first goal of these meetings would be to gain Gaby's trust, by encouraging her to talk about her feelings and problems, and demonstrating that the teacher's motivation to help her is sincere and empathetic. Together, they would develop a list of "unsolved problems" that Gaby agrees she'd like to resolve, and then pick one to start working on. 
For example, they might choose her frequent verbal interruptions during class. Talking about it in more detail, Gaby might reveal that she panics, afraid that if she doesn't ask a question as soon as it pops into her mind, she won't be able to understand the rest of the lesson. Or she might feel she has to get a comment "out of her head" before she can focus. Whatever the reason, just talking about it will help Gaby to become more self-aware. She should also be encouraged to think about the possible consequences of this behaviour (annoys classmates, perceived as attentionseeking, etcetera)—something she has probably never considered. It might require some guidance and leading questions, but thinking about it from a cause-and-effect perspective exercises another executive function skill. This sets the stage for the next step-generating concrete alternatives and working collaboratively on problemsolving strategies. They might try counting every interruption for one day, and then make a game out of seeing if Gaby can reduce the number by one, every day for a week. This would exercise even more executive function skills-monitoring her own behaviour, and practicing inhibition.

If a strategy doesn't work, it shouldn't be considered a failure, but an opportunity to think of another one, keeping in mind that even the process of devising possible solutions is having beneficial effects. And every success will increase Gaby's motivation to work on the next problem.

\section{Conclusion}

Advances in classroom curricula often come hand in hand with increased demands on students to have higher order thinking skills at increasingly younger ages. When they can't meet these demands, whether due to executive dysfunction or simply a lack of experience developing executive function skills, then frustration, failure, dropping out (literally or figuratively), and maladaptive behaviours like meltdowns and shutdowns are the natural sequelae. Pedagogical strategies should therefore address not just what to learn in the classroom, but how to learn in the classroom-cognitively, emotionally, and behaviourally. The latter requires good executive functioning, and the good news is that with recent and ongoing advances in our understanding of how the brain continues to adapt to new learning, even through adolescence and adulthood, we can now devise classroom strategies to hone these very important skills, in all students. 


\section{Notes}

1. This scenario is excerpted and adapted from the author's quarterly column in Exceptional Family Magazine, in an article entitled "Fine-tuning Executive Function \& Emotional Regulation," first published Summer 2008.

\section{References}

Allman, J. M., Hakeem, A., Erwin, J.M., Nimchinsky, E., \& Hof, P. (2001). The anterior cingulate cortex: The evolution of an interface between emotion and cognition. Annals of the New York Academy of Sciences, 935, 107-117.

Blakemore, S.-J., \& Choudhury, S. (2006). Development of the adolescent brain: Implications for executive function and social cognition. Journal of Child Psychology and Psychiatry, 47(3-4), 296-312.

DiPerna, J. C., \& Elliott, S. N. (2002). Promoting academic enablers to improve student achievement: An introduction to the mini-series. School Psychology Review, 31, 293-297.

Doidge, N. (2007). The brain that changes itself: stories of personal triumph from the frontiers of brain science. New York: Viking Adult.

Dweck, C. (2008). Mindset: The new psychology of success. New York: Random House.

Gioia, G.A., Isquith, P.K., Guy, S. C., \& Kenworthy, L. (2000). Behavior Rating Inventory of Executive Function: Professional Manual. Lutz, FL: Psychological Assessment.
Greene, R.W. (1998). The explosive child: A new approach for understanding and parenting easily frustrated, "chronically inflexible" children. New York: Harper Collins.

Greene, R.W. (2009). Lost at school: Why our kids with behavioral challenges are falling through the cracks and how we can help them. New York: Scribner.

MacReady, N. (2011). Predictors of bullying of autistic children identified. Medscape Medical News. Retrieved from http:// www.medscape.com/viewarticle/743027

Meltzer, L., Pollica, L.S., \& Barzillai, M. (2007). Executive function in the classroom: Embedding strategy instruction into daily teaching practices. In. L. Meltzer (Ed.), Executive function in education: From theory to practice (pp. 165-193). New York: Guilford Press.

Powell, K. B., \& Voeller, K. K. S. (2004). Prefrontal executive function syndromes in children. Journal of Child Neurology, 19(10), 785-797.

Spizman, R. F., \& Garber, M. D. (1994). Helping kids get organized. Columbus, $\mathrm{OH}$ : Good Apple. 


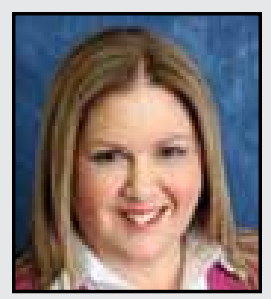

Harriet Greenstone is a psychologist and Director of Centre MDC, a multidisciplinary care centre in Montreal. She is a sessional lecturer at McGill University and lecturer at Vanier College (Continuing Education), and has sat on numerous medical and educational committees serving children with special needs. She has a special interest in how breakthroughs in the study of brain plasticity can be used to improve life skills in this population. 